\section{Expanding the frontiers of learning in educational institutions: The roles of and challenges faced by leaders and followers}

\author{
Azham, Md. Ali $\bowtie$ \\ Universiti Pendidikan Sultan Idris, Malaysia (azham@fpe.upsi.edu.my)
}

Received: 2 December 2011

Revised: 14 February 2012 DOI: $10.5861 /$ ijrset.2012.120

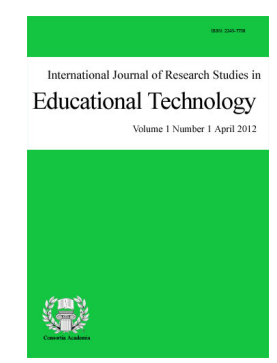

ISSN: $2243-7738$ Online ISSN: 2243-7746

Accepted: 30 May 2012

\title{
Abstract
}

In expanding - nay, breaking - the frontiers of learning in educational institutions, internet is the answer. Indeed, there is now a new mode of learning and teaching with Web 2.0 tools. At the same time, there is the multitude of challenges faced by those with interest in integrating technology with the classroom learning experience. The challenges of concern are internet access, teachers' education, teachers/lecturers modeling for the students, new additional skills or literacies and alternative paths in integrating technology with the classroom experience. It seems that to ensure smooth integration of technology in the classroom, the collaborative or shared leadership style appears to be the most appropriate for those concerned.

Keywords: internet; learning; leadership; educational institutions; challenges; classrooms 


\section{Expanding the frontiers of learning in educational institutions: The roles of and challenges faced by leaders and followers}

\section{Introduction}

The internet is "changing traditional behavior" as daily activities such as shopping, playing games and research are increasingly done online. And as far as education is concerned, many tools are now available for educators to open wide the doors to learning, reducing barriers to information access and to increase the opportunities for learning with colleagues and peers from around the world. In another way of saying, as more information is freely available online with the presence of among others OCW, Open Yale, Open Learn and numerous related projects; tools of collaboration such as wikis and blogs grow in prominence; and means of discovering and networking with others through social network resources become more popular (Siemens and Tittenberger, 2009); education as we know it is in for a substantial change: there is now the expansion - nay, the breaking down - of the frontiers of learning everywhere as long as the internet is at one's disposal.

The specific moves that teachers and lecturers can make in breaking down the frontiers of learning by bringing in the internet into the classrooms have been vividly captured by Siemens (2008). The connectivism guru had among others mentioned:

1. Create a class blog...have students blog. Compile their work in an aggregator - such as PageFlakes that will provide learners with a single page to refer to in order to get an overview of what other learners are blogging about.

2. Use collaborative learning activities - have learners contribute to wikipedia or conduct group work in their own wiki. Better yet, find a colleague at a different university (or school) who is teaching a similar course and create cross-institution collaboration projects.

3. Open your own resources to collaboration and sharing. Start an "english wiki" or "physics wiki" or "psychology 101 wiki" and network with colleagues at other institutions or other countries in developing the resource and keeping it current.

4. Use existing open education resources in planning and delivering course materials. Focus on using a variety of media - games, videos, podcasts, and interviews. Many resources already exist for this type of content....and the list grows daily.

5. Direct students to conference proceedings, recordings, and keynote presentations from recent conferences within the field. Many conferences now record keynote presentations. If the class is focused on a particular theorist or scientist, instead of talking about him/her, direct learners to the source - a recorded keynote or interview.

6. Contribute to the resource pool. When attending conferences, conduct podcast interviews with speakers... or grab a FlipVideo and record the interview...highlight a few key theorists and conduct and email interview and post it on your blog for future class references.

7. Provide learners with resources that will continue to feed their learning after the course is complete. Direct them to blogs, listservs, ning networks, or other communities and networks. The content of a discipline will change. When learners are "plugged in" to a network, they have the opportunity to stay current.

8. Develop learner's skills in participating in and contributing to networks. Detail meta-skills such as evaluating authenticity of information...encourage them to develop conceptual skills - such as 
accepting ambiguity and functioning in uncertain environments. Learning projects that focus on building specific cognitive skills can also be wrapped with meta and conceptual skill development components.

9. Combine worlds - involve 4th year (or graduate) students in interacting with 1st year students (in blogs or wikis, for example). Or, as one faculty member has done at $U$ of Manitoba, have 3rd year students write the text book for first year students (http://webmail.cs.umanitoba.ca/mediawiki/index.php/Main_Page)

10. Bring in virtual guest speakers through elluminate, skype, or ustream. Reduce the centrality of one educator and shift the role of teaching to a network of external experts and other learners (graduate level, other institutions).

In particular, in breaking down the frontiers of learning by bringing in the internet into the classrooms, teachers/lecturers may be interested to know that free Web 2.0 tools such as Diigo, VoiceThread, Ning, Dimdim, Flickr, Word Press, TeacherTube, and Curriki allow learners to among others upload videos and hold real-time discussions about video content; meet as a whole group and as small groups; collaborate and share lesson activities; and develop and share a final electronic portfolio (Burns, 2009). These tools are in short in possession of a number of inherent characteristics that make them more intuitive learning tools, more suited to the promotion of higher-order learning, and more appropriate to an audience of novice technology users, than stand-alone applications, such as word processing software, and older "1.0" uses of the Internet, such as Web sites and even email. All in all, from previously focusing on rote learning, lower-order thinking, and learning as a solo endeavor, with Web 2.0 tools, there is now more "21st century" learning based on creativity, collaboration, higher-order thinking.

\section{Challenges towards having the Internet in the Classrooms}

Creativity. Collaboration. Higher-Order Thinking. Three sufficient reasons as to why the internet needs to enter the classrooms. But there are numerous challenges which interested parties may have to face in making such a move. These include the question on the use of free online apps for digital portfolios; internet safety; localization of software and related materials; students from poor or with disadvantage background and internet hope for their advancement; teachers/lecturers/educational institutions' partnership with peers/community/ businesses; students' mentoring/coaching one another; teachers-students collaboration; and, research and publications on internet and social media use in classrooms in Malaysia/South East Asia. For this work, the issues of interest are internet access; teachers' education; teachers/lecturers modeling for their students; new additional skills or literacies for the students; and, alternative paths for integrating technology with the classroom experience.

\subsection{Internet access}

Obviously only with the internet access made available to classrooms that teachers/lecturers and their students can access many free web tools that can enhance their lessons. Hence, the widespread practice in Malaysia - whereby students and teachers/lecturers need to be in school computer labs for their ICT learning experience to take place - is not acceptable. But, is Malaysia ready to have such classrooms to come into the picture which apparently is an urgent work in progress in countries such the South Korea, France, Japan and Singapore (Kim, 2011) when in some parts of the country there are schools which are still without electricity and running water and that there are schools in urban centers without the internet access?

By and large, to embark on a journey of integrating technology with the learning experience at various educational levels, policy makers at the national level have an important role to play on a number of areas. There is a limit to what teachers/lecturers and others who are directly involved with the Malaysian educational institutions can achieve on their own. For certain, the policy makers need to ensure that Malaysia has the right 
setting for such integration in the form of fast internet connection (and the availability of the necessary devices packed with high quality digital content for the students and their teachers/lecturers) before any other move that they themselves and others in the field may embark upon. Beyond these, however, the ever-accelerating speed of technological innovation can bring stiff challenge to the development and implementation of the so called grand strategy that these policy makers may come out with (Rowell, 2010b). All due to the fact that technology does not wait for policy; it leaps ahead on its own timetable.

Since there is limit to what the policy makers at the national level can do, it goes without saying that other parties such as teachers/lecturers play an important role in successfully integrating technology with the classroom experience. Such a role may however come to void when (as pointed out next) the training that the concerned teachers have to undergo prior to being absorbed in schools may not be giving sufficient emphasis on having the appropriate technologies implemented in the classroom learning experience.

\subsection{Teachers'education}

In the United States, colleges of education are not at the forefront of the so called 21 st Century skills movement. This is as noted Ken Kay (Nussbaum-Beach, 2007a). He argued that teacher preparation programs should be embedding 21st Century skills with their content courses, modeling 21st skills in their instruction and delivery, and helping trainee teachers use Web 2.0 tools to collaborate and build community so that they can get the support they need outside of the classroom once they are on their own. He emphasized that teachers should share best practice first with each other and then beyond their own schools through virtual learning communities. Now, should not all this be found too in Malaysia's teachers' education programs?

Indeed, they should. To be more concise, the concerned institutes of higher learning in the country need to take a serious look at how they are educating the future teachers - even when there appears to be hardly any move from any party to date to have Malaysia to move urgently in integrating technology with the classroom learning experience. Why? For at least three reasons:

First, because technological training could very well become an integral part of the delivery of their lessons not too long in the future after they start teaching or lecturing. That is, following the realization by the power-to-be that it can no longer ignore the move made in the field in a number of countries such as Singapore, the United States and New Zealand. Second, these teacher trainees may one day be among those who shall play an important role in ensuring that the future generations are provided with the kind of education needed for jobs that have not been invented yet. Finally, the day may arrive sooner rather than later when teachers who know how to use technology effectively to help their students connect and collaborate together online will replace those who do not. Surely no one in his or her right mind associated with teachers' education in the country ever want to see his or her students be faced with such predicament?

\subsection{Teachers/lecturers modeling for the students}

For students to learn from the world in the new learning model of the internet age, it is crucial that their teachers/lecturers first own these emerging technologies and the culture that surrounds them. This would mean that Malaysian teachers/lecturers need to form what is known as either Personal Learning Network (PLN) or Personal Learning Environment (PLE). From a website Personal Learning Environments Networks and Knowledge (2010) the following is stated:

A Personal Learning Environment is more of a concept than a particular toolset - it doesn't require the use of any particular tool and is defined by general concepts like: distributed, personal, open, learner autonomy. These conceptual attributes influence the types of tools individuals select to engage in learning. Often, PLEs are presented in contrast to organizational learning management systems... A Personal Learning Network is a structure that reflects relatedness to other people. Information sources (such as Google or databases) can be part of a 
PLN. A PLN is grown by adding new people or connections. A PLN is a reflection of social and

information networks (and analysis methods).

In the same website, it is also mentioned that there is a degree of overlap between the two terms whereby PLE has received greater adoption in higher education, while PLN seems to be more prominent among the so called K-12 (primary/secondary) educators.

As for Siemens, he had this to say on PLEs (Siemens, 2010a): “A variety of informal, socially-based tools comprise this space." And these are:

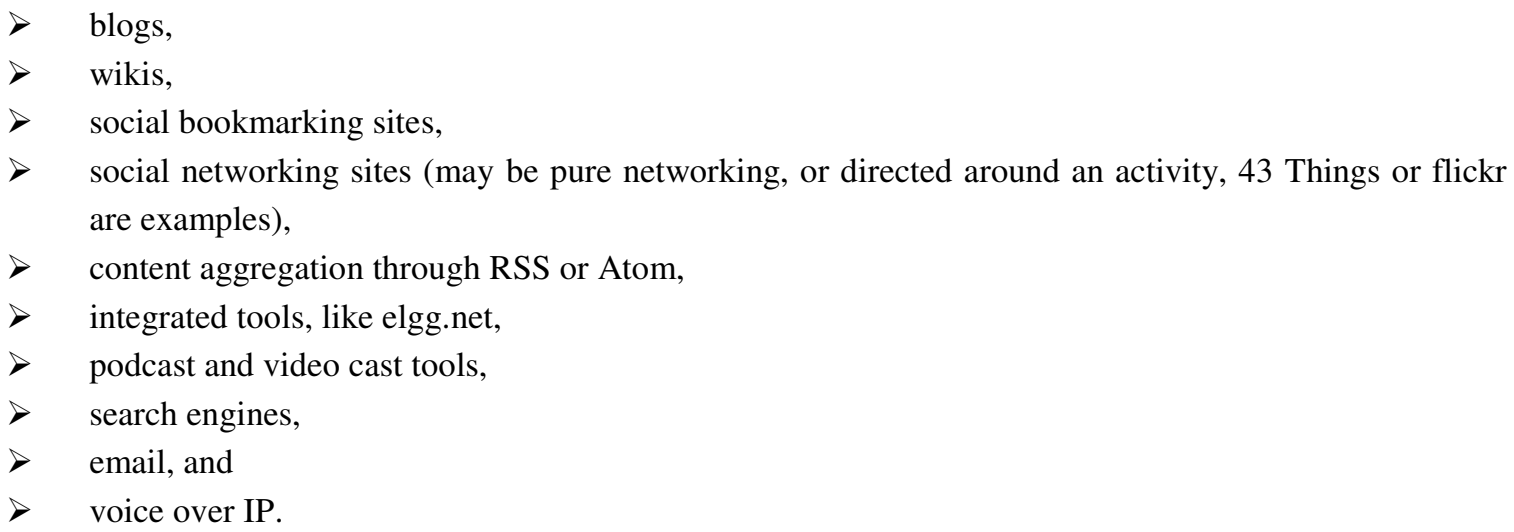

There are problems however in institutionalizing PLE/PLN in the Malaysian context. That is, one may be tempted to ask as to how the overworked but underpaid teachers/lecturers in the schools/institutions of higher learning who in big numbers are lacking in both spoken and written English are capable of building up effective PLNs? Surely such PLNs would be hard to come by without efforts taking place on the power-to-be to reduce the various burdens and to improve the spoken and written English of these teachers/lecturers? So, again, as in the case of internet access mentioned earlier, there is a role to be played by the policy makers for there is a limit to what teachers/lecturers can do on their own. The failure to act accordingly could very well mean that the students are without the role model for the new learning experience. When that is the case, it would seem that the journey to integrate technology with the classroom learning experience shall be longer and more arduous than ever before.

\subsection{New additional skills or literacies for the students}

It seems that various parties are not agreeable on the same set of skills needed by students in the internet era. For the National Council of Teachers of English (NCTE) which is based in Urbana, Illinois, it mentioned the skills needed by the so called twenty first century readers and writers are as follows (National Council of Teachers of English, 2008):

$>\quad$ Develop proficiency with the tools of technology

$>\quad$ Build relationships with others to pose and solve problems collaboratively and cross-culturally

$>\quad$ Design and share information for global communities to meet a variety of purposes

$>\quad$ Manage, analyze and synthesize multiple streams of simultaneous information

$>$ Create, critique, analyze, and evaluate multi-media texts

$>$ Attend to the ethical responsibilities required by these complex environments

In addition to the NCTE, there are well known personalities whose views are probably worth looking into. These are David Warlick, Professor Howard Gardner and Professor Howard Rheingold. David Warlick who was recently named as one of the ten most influential people in edtech by Technology \& Learning Magazine claimed that being able to read text, write a report, and calculate numbers on paper which are basics of the industrial age 
are merely a starting place for twenty-first century literacy which are comprised of the following 4Es (Nussbaum-Beach, 2006):

$>$ Expose them to valuable information from a global electronic library

$>\quad$ Employ digital information in order to accomplish their goals

$>$ Express ideas compellingly so that they not only communicate, but also compete for the attention of the information customers

$>\quad$ Ethical teach them the ethics of operating in an information-driven world

As for the world famous Prof. Gardner known for his work on multiple intelligences, he integrates cognitive science, neuroscience, history, anthropology, politics, economy and human values to offer five states of being that he speculates will be necessary in the new age of learning and work (Sisley, 2011). In his book Five Minds for the Future, he mentioned these to be: disciplined mind; synthesizing mind; creating mind; respectful mind; and, ethical mind. And as far as the famous writer, educator and thinker Professor Rheingold is concerned, in an interview he gave to eLearn Magazine, he mentioned that there are several literacies that the young people need to have (Rowell, 2010a). What he termed as " $21^{\text {st }}$ Century Literacies" are comprised of five literacies: attention, participation, collaboration, crap detection, and network awareness.

Finally, note that Jenkins, Purushotma, Clinton, Weigel, and Robinson (2006) stress on what they call the New Media Literacies (NML) that young people need in the new media landscape. In their work submitted as an occasional paper on digital media and learning for the MacArthur Foundation, they mentioned (Jenkins, Purushotma, Clinton, Weigel, \& Robinson, 2006, p. 4):

Schools and afterschool programs must devote more attention to fostering what we call the new media literacies: a set of cultural competencies and social skills that young people need in the new media landscape. Participatory culture shifts the focus of literacy from one of individual expression to community involvement. The new literacies almost all involve social skills developed through collaboration and networking. These skills build on the foundation of traditional literacy, research skills, technical skills, and critical analysis skills taught in the classroom.

What exactly are these NML that the young people need to have? Here they are (Jenkins et al., 2006):

$>\quad$ Play: the capacity to experiment with one's surroundings as a form of problem-solving

$>$ Performance: the ability to adopt alternative identities for the purpose of improvisation and discovery

$>$ Simulation: the ability to interpret and construct dynamic models of real-world processes

$>$ Appropriation: the ability to meaningfully sample and remix media content.

$>$ Multitasking: the ability to scan one's environment and shift focus as needed to salient details

$>\quad$ Distributed Cognition: the ability to interact meaningfully with tools that expand mental capacities

$>$ Collective Intelligence: the ability to pool knowledge and compare notes with others toward a common goal

$>$ Judgment: the ability to evaluate the reliability and credibility of different information sources

$>$ Transmedia Navigation: the ability to follow the flow of stories and information across multiple modalities

$>$ Networking: the ability to search for, synthesize, and disseminate information

$>$ Negotiation: the ability to travel across diverse communities, discerning and respecting multiple perspectives, and grasping and following alternative norms

$>\quad$ Visualization: the ability to interpret and create representations of data to express ideas, find trends, and identify tendencies 
It appears that the challenge faced by many Malaysian students is this: the various digital skills or literacies demand the presence of self-motivation on the part of the learners. Note that Felt (2010) had stated out the following: “...NML skills support participatory and self-guided modes of learning, both of which tend to better engage students' interest and therefore deliver superior learning outcomes."(Emphasis added.) Related to this, note the following coming from Mr. Tom Preskett, who is a learning technologist at the Institute of Education of the University of London in his article for the online journal Educational Technology and Change (ETC) (Preskett, 2011): "The internet is well suited to learners who are completely self-regulated, aggregating learning resources from a variety of sources, seeking out their own channels of support and collaboration. There has never been a better time to manage your own learning experience." It is notable that in response to this very point, Shimabukuro, the editor for Educational Technology and Change (ETC) had this to say (Shimabukuro, 2011b):

Tom's point is a simple one - anyone stepping into a virtual learning environment expecting to be taught via F2F methods will be lost. Students cannot simply park their bodies at a desk and expect to be taught. They need to initiate or activate the learning process by logging in, clicking, navigating, reading, etc. This is the basic concept of self-motivation in elearning. Without it, nothing happens.

The notion of self-motivation as a primary impetus for learning pervades the entire spectrum of education, P-16 and beyond in both F2F and online classes. The online learning environment, in particular, demands it at the gate, and to enter, everyone must pay the price.

So, are the Malaysian students ready to be self-motivating learners to fit in with the new internet learning mode when the emphasis in going to schools or the institutes of higher learning is merely to pass the examinations leading to rote learning being the approach taken up by many? Without such learners, Malaysia may continue to hope but shall never be able to see the emergence of new learning in the nation's educational landscape.

\subsection{Alternative paths for integrating technology with the classroom learning experience}

There appears to be at least three different paths in relation to the idea of integrating technology with the classroom learning experience. Hence, it could be a challenge for the interested parties to decide on which path to take. One path is as mentioned by Siemens (2007). In his reply to a comment for the blog posting of his, he mentioned: "I think the issue of technology use in classrooms is one that requires a critical evaluation in each context. In some cases, technology can enable and extend classrooms significantly. In others, technology doesn't provide as much value. One answer does not serve all situations."

The leaders taking this path may be associated with the view that there is no need to turn technology into such a big thing in today's education. After all, as in the words of Deutsch (2011), "technology is just a means for teachers to teach for learning and for students to learn more effectively." And, as commented brilliantly by Huett (2009), "no doubt it has to be introduced; however, as far as they are concerned, it should be done in a seamless way and not as an overhead to students and more importantly to teachers as well. The goal ... should be leverage technology and internet only to make it more fun and create a similar environment as in real life..." In short, every time technology enters the classroom learning experience, as noted Nussbaum-Beach in her late September 2007 blog post (Nussbaum-Beach, 2007b), “it isn't an add-on, it isn't one more thing they make us do, it is really an integral part of everyday life and should be an integral part of education."

Another path which may be taken in relation to the idea of integrating technology with the classroom learning experience is to have it totally rejected. There may be at least four reasons for rejecting the use of technology in classrooms. First, the belief that learning can and does take place even when computers, the web, whiteboards, and CMSs are not available! That is, as noted Shimabukuro (2010a), the basic element, interaction among the individuals in the educational setting, can be just as effective today as it is two thousand years ago. Second, the concern that limited class time should be for things one "can only do in a face-to-face environment" and the use of technology which can always take place outside classroom may be getting in the way of that 
happening. Note the following coming from Mota (2010) in response to a March 2010 blog post by Siemens (who mentioned that classrooms may not be the place to emphasize computer use and that the use of technology should take place outside of classrooms):

I totally agree with your view of using technology to extend learning beyond classroom walls, not have every student with a computer working in class. For one, it's a nightmare to get everything to work, and it's a missed opportunity to do other things you can only do in a face-to-face environment.

Class time should be used for modeling, tutoring, clarifying, organizing, reflecting together, developing good communication and collaboration skills, etc. One or two computers with an Internet connection, a digital board or a video projector are very useful in class, but then students should work online on their own or use a media lab.

The third reason for rejecting the idea of technology integration with the classroom experience is concerned with the issue raised by Dr. Nellie Deutsch. She mentioned (Deutsch, 2010):

I never thought I would say this but instructor enthusiasm for technology can turn sour in the classroom. Instructors can overuse technology if they don't plan the course carefully. I have heard this statement for the past 15 years but never really related to it until now ...

My research findings on instructor experiences with implementing technology in blended learning courses in higher education indicate that learning how to use a new gadget outside the classroom does not mean knowing how to use the tool effectively in the classroom for instruction and learning. As Garrison and Onken suggested: It's easy to get carried away with technology. We've seen lots of colleagues input a particular technology into a course just because they can. (Emphasis already around)

As for the fourth and final reason for the classroom technology rejection, it is concerned with all the talk and pontification that technology integration with the classroom experience fit in with the youth of today. That is, in the view of those negating the idea of technology integration with the classroom experience, these may be nothing more than wishful thinking on the part of the so called edubloggers. Note on the following comment made by Ryan (2007) in response to early September 2007 Siemen's blog post:

When I look around my classroom, I really don't see a bunch of disaffected 'digital natives' staring back at me. Many bloggers write about a homogeneous mass of kids who, by and large, don't actually exist. This simplistic reductiveness is, I believe, born of inexperience and ignorance; many of those offering opinions aren't teachers and haven't spent much time in schools or with young people apart from their own kids. As such, their opinions are certainly valid but need to be recognized for what they are. Much of the supposed iconoclastic theory informing much debate comes from the same place; people who are advocating complete change, who think that we need to completely abandon everything and start getting learning agents to facilitate learning via second-life based virtual nodes really need to think more about what schools do and what they're for. Or even go and visit a few schools (actual schools in session, that is, not schools that are hosting conferences!) I agree that change is needed, that it is coming and that technology offers probably the most powerful tools for facilitating these changes. I also recognize that, in order to initiate change, it is often necessary to overstate a case. The case for Ed 2.0 has been overstated in many cases, but there's a lot of valuable insight behind the hyperbole, pseudo-science, dodgy research and general waffle. It could well be time to start engaging and stop pontificating.

It may be worth pointing out that that Ryan (2007) is not alone with such view. Finnigan (2011) in a 
Expanding the frontiers of learning in educational institutions

comment made in response to an article appearing in the online journal eLearn Magazine had among others mentioned:

These so-called digital natives use their technology in a very narrow context of gossip and entertainment. Most of the time it's not even gossip, but simply inane messages posted to relieve boredom or seek attention. They do not use the technology for any constructive purposes. Mobile phones, Twitter and Facebook have facilitated and amplified this babble. In education, the medium is not the message. Any message, be it printed, video, online, or mobile, that requires concentration and thought is treated lightly or outright rejected. The key problem is lack of concentration. Students seem to be increasingly unable to concentrate and focus on a task for any length of time. Mobile phones are not designed for periods of concentration. Twitter and Facebook are not designed for periods of concentration. Even as surfing the Web (eg. Wikipedia or other forms of research) is borderline. The distraction may already be there, but these technologies feed it. Students must be able to sit down and focus on a task for more than 5 minutes at a time without being constantly distracted or seeking distraction. You may ask why? Why not let them be distracted, as long as they eventually get the work done? The problem is that they are not being trained to concentrate, so when concentration is required, they can't cope. And often, extended periods of concentration are needed to get something done. Also, weaker students who are constantly distracted may *never* get the job done properly. If we encourage this in our eagerness to appear trendy and with it and progressive, or as a way to avoid throwing in the towel, then we have failed as educators... I don't think that this is just about me and my learning habits - I believe most things need concentration to be learnt properly. I have no problem with students using hand phones and online technologies to augment their learning, even in class, and have developed Facebook pages, blogs and other resources in an attempt to guide them towards this. However, these technologies are designed and marketed in complete opposition to this form of use, and so most students are usually unresponsive. Like I said, it's the having to think that switches them off, not the medium of communication.

Finally, the third and last path to take in relation to the idea of integrating technology with the classroom learning experience is that efforts must take place to bring systematic moves in primary, secondary and tertiary levels of education nationwide to take into consideration technology now and for the future. It may be safe to say that those taking this path have the understanding that there is a need for changes taking place in the education field to be aligned to societal changes. But, there is perhaps a need for caution in taking this path. As stated Shimabukuro (2011a):

Plunking innovation into an existing curriculum is not the end all. In fact, it is only the beginning of a long period of trial and error, of countless ongoing additional innovations, tweaks, and changes to develop a model that actually works for a given teacher with a given group of students in a given learning environment.

To underscore the complexity of what we do as teachers, we need to point out that these working models are always evolving, even as we're applying them in current classes. They're never the same horizontally among different classes and vertically within the same class, day to day. In fact, they need to be adjusted for each class as well as for small groups and individuals.

In a very real sense, teaching is a lot more complex than brain surgery. The sheer number of critical variables defies attempts to turn teaching into a routine procedure, a science, leaving it in the realm of the arts where intuition still remains the best guide to practice.

Also, those taking the path of full integration of technology at various levels of the education system may need to be reminded that classroom learning is not the only kind of learning around. In fact, these days teaching and learning are increasingly seen as things which take place beyond the book, the teacher, or the classroom 
(Reynolds, 2006). Hence, there is a need to keep this broad picture in mind in working towards integrating technology with the classroom learning experience. Better still, their pursuit for full integration of technology at various levels of the education system should perhaps be placed in the context of a bigger pursuit of a complete view of learning from cradle to grave needing equal level of technology integration throughout.

\section{The Way Forward}

It may be safe to say that policy development is a complex process with many variables that need consideration and teamwork to ensure successful development and implementation (Cooper, Fusarelli and Randall, 2004). This is especially true when it concerns the idea of integrating technology with the classroom learning experience where there exist various issues which need to be dwelt with. But help may be on its way with the formation of "study circle dialogues" which can provide policymakers with information from experts in the field of education as well as from parents, students, and the community (Rouk, 2000). The study circles help policymakers gain a better understanding of the public needs and interests. In this regard, the policymaking also known as leadership from within and outside the educational institutions can be somewhat attended to by the contributions of many.

Note the following coming from Siemens in his March 2010 blog post (Siemens, 2010b): "Grand schemes and plans benefit from contributions of individuals. Ideas of reform should be shaped by the voices of those who are impacted. Leadership in education should concern itself with creating spaces for vibrant discussion and use these spaces as a means to test their ideas of change." When help come in the form of contributions from many, the policy makers also known as leaders should find it less cumbersome in working out a successful integration of technology with the classroom experience which as stated out Siemens in his March 2010 blog post entails among others the following (Siemens, 2010b):

Leadership also faces basic tasks of managing supplies of technology, repairs, ensuring vendors (hardware and software) are held to established procedures and standards. It is difficult to establish the proper mix of pursuing innovation while addressing practical day-to-day details. Once Magellans are in the hands of students, the inevitable question of maintenance arises. What happens if hardware fails? What about new versions of the hardware or software? What about in-class technologies such as interactive whiteboards and LCD projectors? Initiating a project is often easier than sustaining it.

And then there is the difficulty of the social and organizational dimensions of change. Change management and incentive strategies can help move an agenda forward. However, leaders don't need people who do what has been planned. Today, leaders need co-leaders - people who are active in experimenting and exploring future directions.

Leaders face a large scale rebalancing of education. They need to find new points of balance: between teacher/learner, planning/emergence, organized/complex, top-down/grassroots. The entities that will shape our future are already in play. It's about new and novel combinations, finding new states of relatedness.

If one were to check on the various types of leadership theory, invariably the picture emerged points to individuals who lead. For example, in the case of the transformational leadership, Kouzes and Posner (2002, as found in Nussbaum-Beach, 2010a) states that there is an individual at the head - the Transformational Leader who seeks to transform the organization, promising to the followers that in this process will be transformed in some way. But, would anyone dare to deny that none of those in an organization including those so called leaders who are normally persons in the position of formal authority is as good as all of those in the organization? Hence, there is a need for a re conceptualization of leadership to include the wisdom of the crowd. In other words, there is now collaborative or shared leadership to emerge from community based participation as opposed to leadership separated from others and predetermined by a set of behaviors of those in charge. 
With leadership to be a shared responsibility for a shared purpose, there should emerge committed work by all in the educational community. As mentioned Nussbaum-Beach (2010a), "everyone becomes engaged and has ownership in the improvement initiative." And, leadership is as far as she is concerned no more the case of "do it because I say so mentality" or a "do it because I am so awesome that I inspire you to participate mentality" or "do it for the team mentality." Instead, in its everyday sense, as she mentioned in her blog post (Nussbaum-Beach, 2010a):

There will be a realignment of power and authority from individuals to groups. Brave superintendents and principals will learn to release personal authority and instead develop capacity in their faculties to use their newly gained personal power in ways that enhance the value of the whole. Teachers need to see school change as a collective endeavor that they no longer can abdicate to formal leadership. In a learning community, leadership becomes the right and democratic duty of each individual in the school and in the transparent venue of learning together in the presence of others - excuses, laziness, and blame for why change isn't managed effectively or truly effective innovations aren't implemented isn't tolerated.

Nonetheless, it may not be surprising to find that some parties may still feel threatened by collaborative or shared leadership even when technology integration in the classroom process necessitates such move. This is understandable: school heads and top administrators in the institutions of higher learning have the fear that if they empower their teaching staff things could get out of control. This is very similar to the belief that teachers have on empowering their students. As for the political executives and top administrators from the federal ministries, departments and agencies, the collaborative or shared leadership would be out of the ordinary for they are used to a Malaysian administrative context marked with subordinates coming from the educational institutions following their instructions without raising even a single question.

But, from discussion above on the various issues that are part and parcel for bringing technology into the classroom learning experience, it appears that all of these parties from within and outside the educational institutions occupying the seats of power or authority have no other choice: they have to make an intentional shift in culture whereby replacing the top down leadership mentality for a collaborative or shared leadership model. There is also another reason for doing such a shift. That is, with the presence of new learning mentioned earlier which gives primacy to the idea of collaboration among learners in a learning network or environment, the leadership style that fits in with such learning mode within an educational institution cannot perhaps be anything other than collaborative or shared type. Such consistency between the leadership style (where all need to come together to lead since none is bestowed with complete knowledge and understanding) and the learning mode (where all learn best together) should strengthen the belief of all parties that the path of collaboration is indeed the right one for them. This can only mean greater probability for success in integrating technology with the Malaysian classrooms.

All in all, much sacrifice shall perhaps be needed from all concerned when parties in the position of leadership are now asked to identify with their subordinates as peers. But, as long as there is a clear understanding that Malaysia today may not find it easy to compete with others without its education landscape bringing in technology into the classroom so that its human resource output is able to take full advantage of the internet, no sacrifice shall perhaps be of too much to make. The internet has made it a necessity for Malaysians to change. Change agents are who we need to be. Leaders and followers designation have become of secondary importance. That is, under the Malaysian sun, each and everyone associated with the educational institutions is playing the role of collaborating with others as equal members of communities to pursue the path of redefining teaching and learning and leveraging upon Web 2.0 tools in doing so.

\section{References:}

Burns, M. (2009, June). Threading, tagging, and higher-order thinking. eLearn Magazine. Retrieved from 
http://elearnmag.acm.org/featured.cfm?aid $=1595442$

Cooper, B. S, Fusarelli, L. D., \& Randall, E. V. (2004). Better policies, better schools: Theories and applications. Pearson Education, Inc.

Deutsch, N. (2010, August 9). Instructor enthusiasm for technology turns sour in the classroom. Message posted to http://nellie-deutsch.com/2010/08/teacher-facilitation-or-teacher-teaching/

Deutsch, N. (2011, February 8). Teaching for learning. Message posted to http://nellie-deutsch.com/2011/02/teaching-for-learning/

Felt, F. (2010, July). Making education (double) count: Boosting student learning via social and emotional learning and new media literacy skills. eLearn Magazine. Retrieved from http://elearnmag.acm.org/archive.cfm?aid=1839556

Finnigan, D. (2011, January 19). Teachers vs. cell phones: Mobile devices win. eLearn Magazine. Comment posted to http://elearnmag.acm.org/archive.cfm?aid=1925038

Huett, N. (2009, August 14). 21 st century workforce readiness. Comment posted to http://21stcenturylearning.typepad.com/blog/2009/02/newport-news-public-schools-is-moving-quicklyto-address--learning-in-the-21st-century-its-barriers-and-its-possibilities.html

Jenkins, H., Purushotma, R., Clinton, K., Weigel, M., \& Robinson, A. (2006). Confronting the challenges of participatory culture: Media education for the 21st century. Chicago: The MacArthur Foundation. Retrieved from http://www.projectnml.org/files/working/NMLWhitePaper.pdf

Kim, S. (2011, July 20). South Korea ditching textbooks for tablet PCs.USA Today. Retrieved from http://www.usatoday.com/tech/news/2011-07-20-south-korea-tablet-pc_n.htm

Mota, J. (2010, March 17). Changing the system at a national level. Comment posted to http://www.connectivism.ca/?p=249

National Council of Teachers of English. (2008). NCTE framework for 21 st Century curriculum and assessment http://www.ncte.org/library/NCTEFiles/Resources/Positions/Framework_21stCent_Curr_Assessment.p df

Nussbaum-Beach, S. (2006, November 29). Internet safety. Message posted to http://21stcenturylearning.typepad.com/blog/internet_safety/

Nussbaum-Beach, S. (2007a, June 27). $21^{\text {st }}$ century assessment. Message posted to http://21stcenturylearning.typepad.com/blog/2007/06/21st-century-as.html

Nussbaum-Beach, S. (2007b, September 30). Making change happen. Message posted to http://21stcenturylearning.typepad.com/blog/2007/09/making-change-h.html

Nussbaum-Beach, S. (2010, February 14). The notion of leadership is shifting. Message \& response to comment posted to http://www.21stcenturycollaborative.com/2010/02/leadership/

Personal Learning Environments Networks and Knowledge (2010). Week 1: A tour of PLEs and PLNS Diagrams, discussions, examples. Message posted to http://connect.downes.ca/cgi-bin/page.cgi?post=44665

Preskett, T. (2011, January 4). The issue of self-motivation in F2F and online learning. Educational Technology \& Change. Retrieved from http://etcjournal.com/2011/01/04/the-self-motivated-learner/

Rouk, U. (2000, November). Policymakers build bridges to the public. Southwest Educational Development Laboratory (SEDL), 13. Retrieved from http://www.sedl.org/policy/insights/n13/2.html

Rowell, L. (2010, February). An interview with Howard Rheingold. eLearn Magazine. Retrieved from http://elearnmag.acm.org/featured.cfm?aid=1721932

Ryan, K. (2007, September 28). Pots, kettles, and other small appliances of like appearance. Comment posted to http://www.connectivism.ca/?p=94

Shimabukuro, J. (2010, December 11). A lesson from Haiti: Despite the lack of IT, learning happens. Educational Technology \& Change. Comment posted to http://etcjournal.com/2010/12/11/a-lesson-from-haiti-despite-the-lack-of-it-learning-happens/

Shimabukuro, J. (2011a, January 2). Critical Importance of Social Interaction in Online Courses Educational Technology \& Change. Retrieved from http://etcjournal.com/2011/01/02/7050/

Shimabukuro, J. (2011b, January 6). The issue of self-motivation in F2F and online learning. Educational 
Technology \& Change. Retrieved from http://etcjournal.com/2011/01/04/the-self-motivated-learner/

Siemens, G. (2007, April 10). Future hope against today's reality. Comment posted to http://www.connectivism.ca/?p=86

Siemens, G. (2008, February 15). Getting started with connectivism/networked learning... Message posted to http://www.connectivism.ca/?p=103

Siemens, G. (2010a, March 12). Learning or management systems? Message posted to http://www.connectivism.ca/?p=243

Siemens, G. (2010b, March 14). Changing the system at a national level. Message posted to http://www.connectivism.ca/?p=249

Siemens, G., \& Tittenberger, P. (2009). Handbook of emerging technologies for learning. Document posted at http://umanitoba.ca/learning_technologies/cetl/HETL.pdf

Sisley, M. L. (2011, March). Learning 2.0: How digital networks are changing the rules. eLearn Magazine. Retrieved from http://elearnmag.acm.org/archive.cfm?aid=1966300 
Azham, M. A. 